\title{
ENHANCING INTERPERSONAL COMPETENCY \\ THROUGH SOFT-SKILLS TRAINING WITH \\ REFERENCE TO FIRO-B
}

*Dr.Umashankar. K **Ms. Charitra HG

\section{Abstract :}

The significance of interpersonal skills is fundamentally increasing as the productivity of the workplace is directly linked with the quality of relationship among the employees. Therefore, the researchers found the necessity of understanding the level of interpersonal competence of the young professionals so that they can go on par with the existing and experienced professionals. In order to gauge the interpersonal competence, the researchers adopted FIRO-B (Fundamental Interpersonal Relationship OrientationBehaviour) which is considered as a significant tool in assessing the interpersonal skills of the professionals.

The study focused on assessing the interpersonal skill requirement of the young professionals. In this regard, the FIRO-B was administered on both young Probationary officers of XYZ bank and the teaching professionals of Krupanidhi College. Based on the respondent survey, the researchers tried to understand the required interpersonal skills for the budding professionals. In continuation, the paper also suggests the effective pedagogical tools to nourish the interpersonal excellence among the budding professionals.

Keywords : FIRO-B, Budding Professionals, Teaching Professionals, Behavioural Intelligence, Selfconcept.

\section{Introduction}

The interpersonal competency has been gaining profound importance in this contemporary world of corporatocracy. Indeed, a careful observation into the nexus of human relations operating at workplace, one can find out the complexity involved in establishing and managing workplace relationships. Even if the good relationships are established, the consistency and quality of the established relationships have to be taken for consideration.
Moreover, no human wants to live in isolation as their instincts are driven or triggered by socialization and they want to interact and share their social craving among the people may be at workplace, personal or social settings. Consequently, people do face some subtle challenges in maintaining the healthy or cordial relationships in the long-run. Sometimes, the relationships may be impaired or injured due to some petty annoyances or mis-understandings. As a result, the bi-products of strained workplace relationships like; stress,

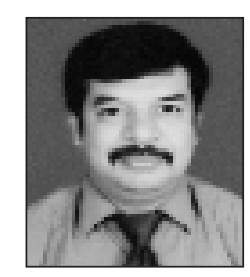

I Author

Dr. Umashankar

Faculty,

Dept. of Behavioural Science,

Manipal University,

Bangalore Campus, Bangalore.

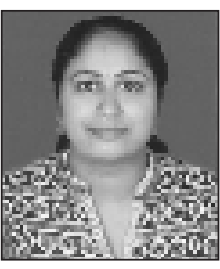

II Author

Dr. Chaitra H.G.

Assistant Professor,

Department of English,

Krupanidhi Degree College, Bangalore 
anxiety, jealousy, unfair competitions and frustrations contribute to decrease the work efficiency of the employees.

Indeed, the psychological and communication research in the domains of interpersonal relations at workplace has been throwing sufficient insights on the nexus of interpersonal relationships and the factors that influence the sanctity of relationships at workplace. Charles Berger and Richard Calabrese (1975) in the Initial Interaction Theory inferred that the first interaction in the group or between the individuals is characterized by some uncertainties like cognitive and behavioural. Wherein, the individuals may be disoriented or perplexed about the cognitive or the behavioural response that they may get from the other party. Hence, these theorists opined that the parties involved in the interaction should be aware of the cognitive state (attitude, perception and thoughts) and behavioural styles (response or style of reaction). As a result, the individuals may be free to interact with the individuals with/without minimal inhibitions.

The Social Exchange Theory of George Homans (1958) propounds that the social relationships are based on cost-benefit analysis wherein the individuals involved in social exchanges have subtle intentions of getting psychological or monetary rewards. Besides, the basic assumptions of this theory are:

- Humans always aspire for returns out of a relationship and discard negative outcomes.

- Humans are logical and social animals

- The usage of gauging system to measure outcomes out of a relationship that varies from individual to individual.

With reference to the above concepts on interpersonal relationships, the researcher has also attempted to understand the human relations prevailing at workplace set-up. In this regard, the conceptual observations infer that the employees feel to have emotional exchanges rather than exchanging the thoughts mechanically all the time. In order to understand better the workplace relationships, the researcher must treat the employees as emotional beings not as the humanoids. Besides, the interpersonal relationship at workplace is a complex nexus which is made up of emotional filaments that influence the social or cultural or behavioural exchanges that take place.

\section{Understanding FIRO-B}

Fundamental Interpersonal Relations Orientation - Behaviour (FIRO-B) is a concept developed by Will Schutz (1953) to define various behavioural competencies required for a professional to maintain healthy relationships at workplace. Later, FIRO-B has been used as an assessment tool to determine the interpersonal relations competency of the individual employees. Further, the under competency of Interpersonal Relations, he brings in two behavioural anchors like Expressed and Wanted. Further, each behavioural anchor comprises three subanchors like Inclusion, Control and Affection.

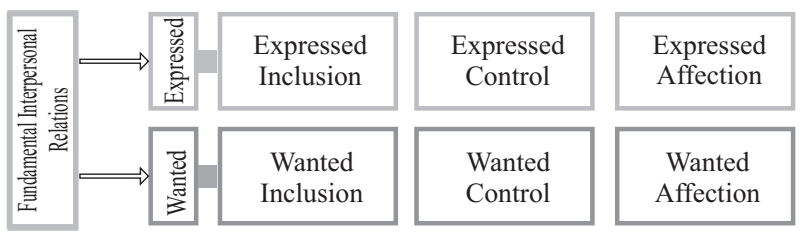

Fig 1 - Components of FIRO-B

In addition, it was inferred that the behavioural competency posited by FIRO theory is just an inner reflection of one's self-concept. It is inferred that the self-concept is based on iceberg model wherein $10 \%$ of self is visible 
outside and $90 \%$ is hidden from the general view. As per the FIRO theory, whatever an individual wanting for himself, the same would be expressed toward others.

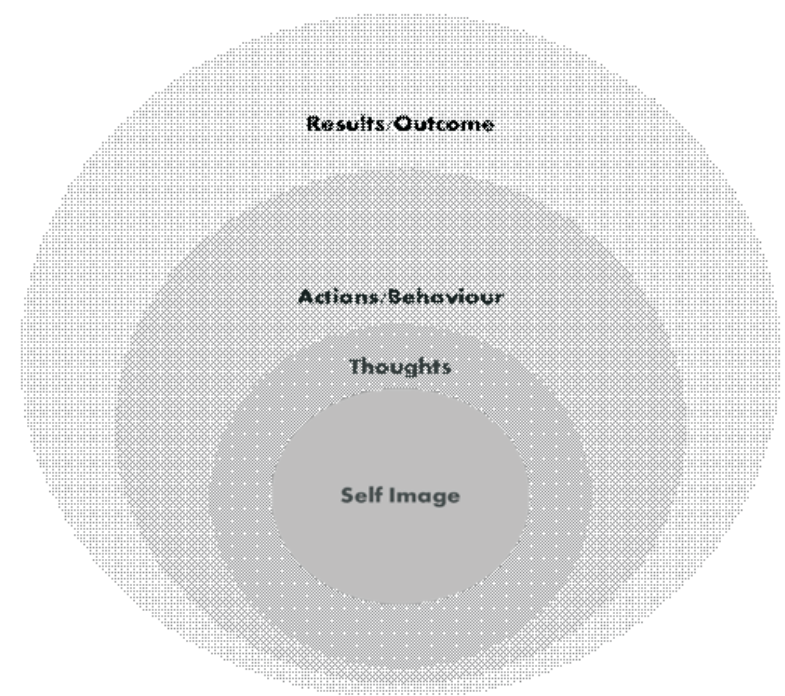

Fig 2 - The concept of inner-self as expressed in FIRO-B

Further, the human mind evaluates the external behaviours of other in relations to the selfconcept developed by the particular individual and based on that the behaviours of each individual is manifested into actions and finally affecting the relations positively or negatively.

\section{Purpose of the Study}

Considering the importance of interpersonal relationships at workplace, it is a primary obligation on the B-Schools to nurture interpersonal excellence in the budding professionals. It is an evident fact that the reputed B-Schools have incepted Training and Development in order to nourish behavioural competency of the students, however, the expected focus is not made on building required interpersonal skills for coping with the challenges faced in maintaining effective interpersonal relationships at workplace.

The study also infers that the postgraduate students' interpersonal competency in spite of their academic training may not be as good as the interpersonal skills pursued by the experienced professionals who have faced diversified human behaviours at every pace of their professional journey. As a result, they have learnt the ways of handling the subtle relations, diplomatically, without causing any emotional wounds in others. In continuation, the purpose of the study also aims at suggesting the effective tools which can incorporated while training conducting sessions of interpersonal competency.

\section{Limitations of the Study:}

The study proposes various tested and effective tools to enhance the interpersonal competency among the postgraduates. The tools also focus at reengineering the self-concept of the budding professionals. However, the simulations training tools may not be equivalent to the assorted human behaviours and sophisticated human relations in real corporate world.

\section{Incorporating FIRO-B for Soft-skills Training at B-Schools}

It is an evident fact that the interpersonal skills are indispensable for an astute professional at workplace and the budding professionals have to be trained to understand the subtle behaviours of the prospective colleagues and make the official ambience a better place to work and contribute for the success of the company.

In this regard, the B-Schools must also understand the fact that the MBA Graduates may not have sufficient skills in maintaining professional interpersonal skills as they are not exposed to such web of complex relations. Indeed, the students may be very much skillful and smart enough to deal with the logical or reasoning challenges posed in academically 
regulated challenges, however, they may not be ready to face the real world in terms of diversified human behaviours.

Considering the importance of the interpersonal skills at workplace, the researcher conducted a survey in order to ascertain the fact that interpersonal competency differ from the postgraduate students to the elderly professionals who have sufficient experience in dealing with various behaviours diplomatically in day to day situations.

\section{Methodology}

The researchers selected samplings from two diversified groups by administering the FIRO$\mathrm{B}$ questionnaire and the aim was to see if there is any differences in the scores of two diversified samplings pertaining to the interpersonal skills. Further, the researchers have also considered the variables like gender, however, the authors have chosen the samplings from similar socio-cultural, age group and geographic backgrounds of each group.

\subsection{Instrumentation}

FIRO-B - Fundamental Interpersonal Relationship Orientation - Behaviour (Schutz, 1994) is considered for the purpose of data collection. The questionnaire has 54 items on 6 point scale. The Questionnaire has two major divisions like Expressed(Preference to do, Initiation, observable action)and Wanted(one's willingness for others to initiate, One's intense preference to be the recipient) and each division has three sub-divisions like Inclusion (recognition, belonging, participation), Control(influence, leading, responsibility) and Affection (closeness, warmth, sensitivity).Each subdivision carries maximum score of 9 and the total score of 54 .

\section{Graph 1 - Maximum Scores for each component in FIRO-B}

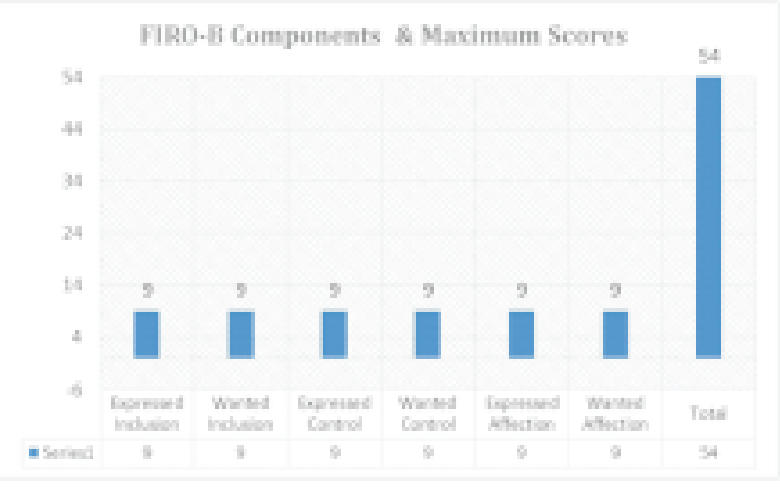

Further, the interpretation for the scores for the individual cell of FIRO-B is reflected in the following table:

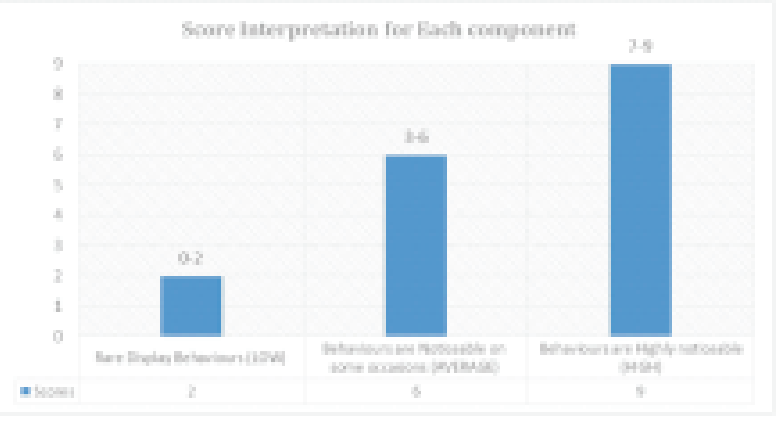

\section{Graph 2 - Scores Interpretation for each component in FIRO-B}

The below graph No.3 shows the score interpretation for Wanted and Expressed

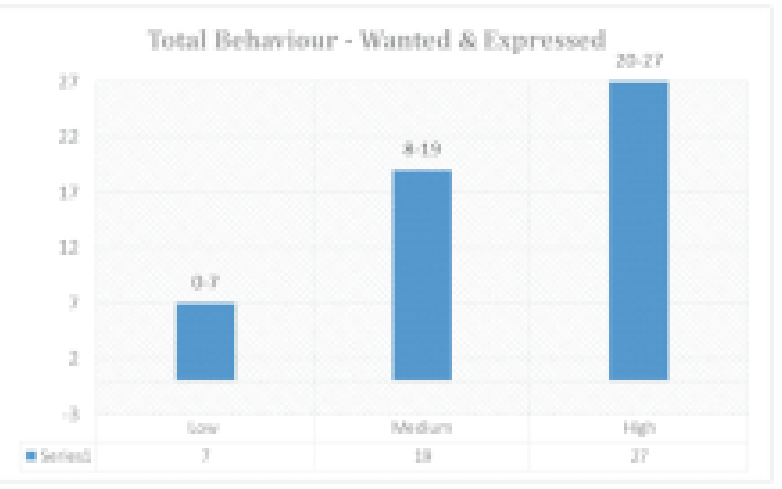

Graph 3 - Total Behaviour Wanted and Expressed 
Further, the overall scores of FIRO-B reflects on the interpersonal needs of the respondent as reflected in the below graph:

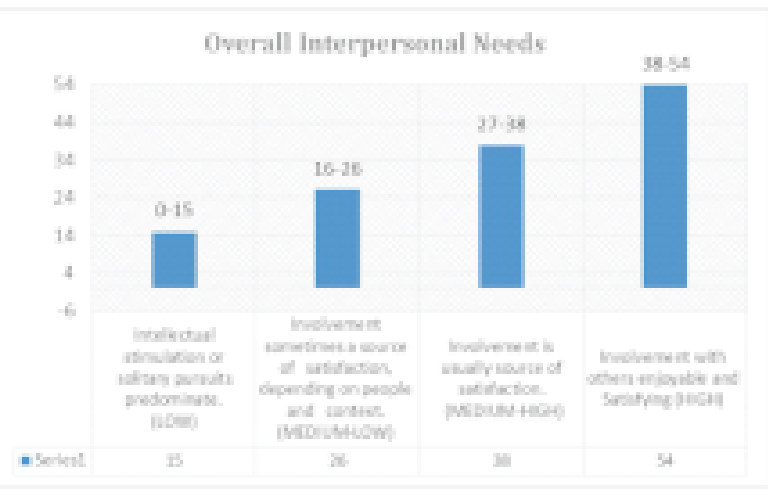

\section{Graph 4 - The overall Interpersonal Needs of the respondent}

6.2. Profile of the Respondents and the organization

- Zest Global Education Services Pvt. Ltd (Name Changed), located in Bangalore, is involved in training the probationary officers of various banks and it provides both long-term (12 months) and short term (it may vary as per the clients' requirement) programs to various private and public sector banks. The training primarily focuses on enhancing operational skills and behavioural skills of the officers.

- Probationary Officers of XYZ Bank: The POs of XYZ bank are pursuing Postgraduate Diploma in Banking and Finance offered by reputed university. All the respondents are from B.Tech background and they are basically from Andhra Pradesh/Telangana.

- Krupanidhi Degree College: Krupanidhi Degree College is affiliated to Bangalore University and it offers various UG and PG Programs on campus.

- Staff members of Krupanidhi Degree College: The staff members comprise the teaching faculty and they all belong to Bangalore. The respondents belong to same socio-cultural background and they are in the age group of 30 to 45 years. Academically, the respondents are postgraduates and most of them are pursuing PhDs.

6.3. Data Collection: The FIRO-B inventory was administered on the Probationary officers (20 Male +20 Female) and the professors (20 Male and 20 Female) simultaneously and the scores have been derived based on the gender variable. During the administration of this inventory, the ethical issues have been duly considered.

6.4. Data Interpretation : The interpretation is based on the FIRO-B version 1996 and the below graph (4) reflects on the average scores of the probationary officers on various dimensions of Interpersonal Relationships like Expressed and Wanted. The scores include the average scores of both male and female:

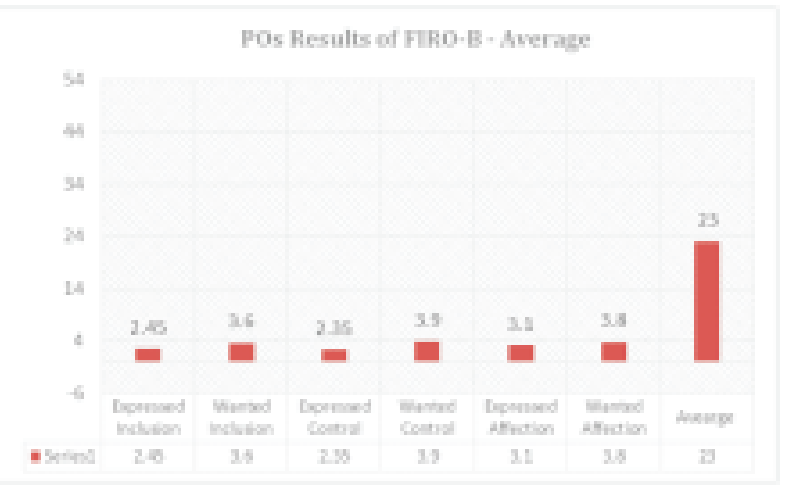

\section{Graph 5 - The average scores of Male and} Female Probationary Officers

The graph reflects that the POs have scored 2.3 in the component of Expressed Control which means the POs they do not wish to take high responsibilities nor the accountabilities at workplace and they prefer to be in isolation or they do not want their behaviours to be displayed in the organization. The POs have scored similar in the Expressed Inclusion 
(2.35) which reflects on their solitude behaviour which is not compatible for a leadership role. The scores of Expressed Affection (3.8) also infers that the POs do not believe in expressing their sensitivities or concerns towards the people as they think that it is waste of time. The scores in Wanted Inclusion, Control, and Affection (3.6, 3.9, \& 3.8 respectively) and the average score of Wanted (11.3) reflects that they have average scores which are neither high nor low. However, this can be inferred that the POs may not feel convenient in working with the teams. Further, these scores also reflect that these youngsters wait for the invitations to perform the tasks.

The overall interpersonal need score (23) shows that the POs are in Medium-Low level of interpersonal skills which can inferred as the students may not enjoy all the time in the midst of the company and they have only a selected few people with whom they wish to interact.

In continuation, the researchers administered FIRO-B on the professionals who are in the teaching domain. Further, the research also aimed at a comparative analysis of the interpersonal needs of the budding professionals and the working professionals. The following graph reflects on the FIRO-B scores of the teaching professionals:

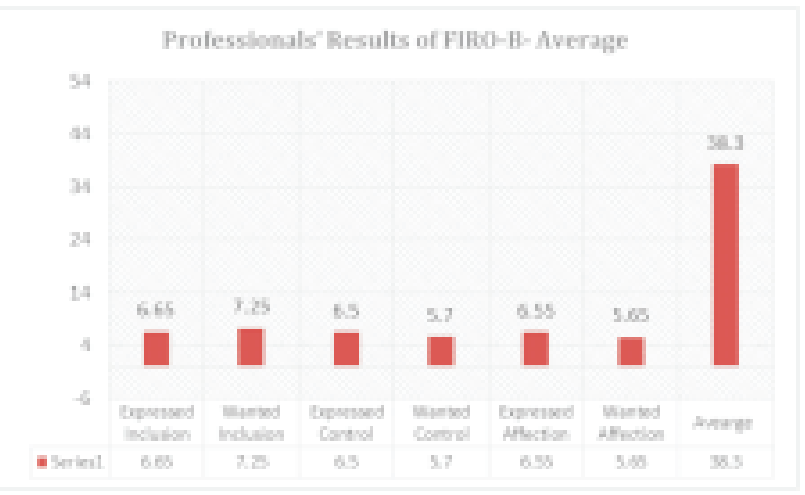

\section{Graph 6 - The average scores of Male and Female Teaching Professionals}

The above graph shows that the professionals have scored reasonable in Expressed Inclusion, Control and Affection (6.65, 6.5 and 6.55 respectively) and the total score of Expressed is 19.7. It can be inferred that these scores are high and the respondents are active in their social or workplace responsibilities. Besides, they are also good team-players and they wish to include the people in their professional endeavours.

In the domain of Wanted that is Inclusion, Control and Affection (7.25, $5.7 \& 5.65$ respectively), the respondents have scored the total average of 18.6. This can be interpreted as the professionals are in the border line between Medium and High and they may never think the invitation to perform at workplace is an obligation. They tend to be with the group. The overall interpersonal need score of the professionals (38.3) shows that the teaching professionals are good at interpersonal skills and they are good team players.

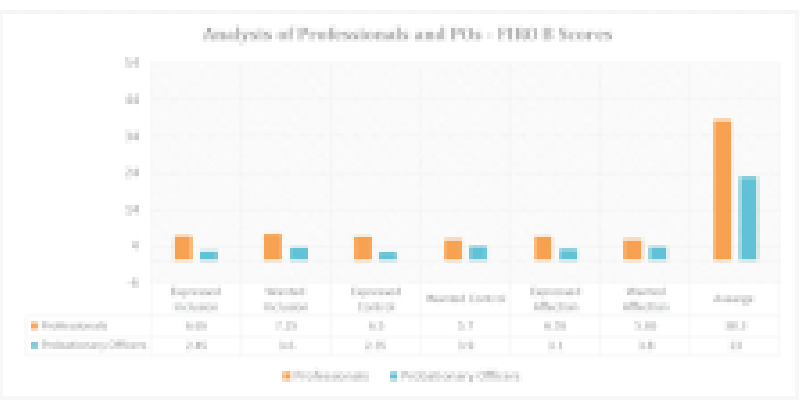

Graph 7 - The comparative Scores of Probationary Officers and the Teaching Professionals

The above Graph reflects on the scores of the young probationary officers and the Teaching Professionals. Evidently, it can be inferred that the teaching fraternity has high interpersonal skills than the young probationary officers. It is also a fact that the interpersonal skills displayed the professionals are very much congenial at workplace compared to the naïve interpersonal skills displayed by the young Probationary Officers. 


\subsection{Survey Findings:}

- The young Probationary Officers' scores in Wanted and Expressed are comparatively low. This shows that the young officers may have to work on improvising their emotional sensibilities towards the workplace relationships.

- It is also signified that the young officers are not completely equipped with the interpersonal skills to deal with the challenges that arise out of workplace conflicts or the mind games that people play at workplace.

- The young officers have to be trained on assertiveness and empathy that may help them to enhance their expressed and wanted control domain.

- The comparison between the working professionals and the Probationary Officers pursuing their education has revealed that the young officers have a gap of required interpersonal excellence that has to be bridged before they take off their professional journey.

\section{Suggested Training Programs for the Young Officers}

Based on the review of literature, it is inferred that the self-concept plays a major role in the individuals' interpersonal excellence and the FIRO-B, which is based on the self-concept, focuses on the delicate aspects of an individuals' emotional agility, perception, attitude and personal ideals. As a result of one's personal beliefs and emotional agility, the quality of interpersonal relations or skills are determined.

It is also inferred that the soft-skills training programs that are offered to these young professionals have to focus more on nurturing their concept of self that could transform their interpersonal efficacy in dealing with the relationships and bringing more life into to their workplace emotional transactions.

Considering the gap the interpersonal skills of the young probationary officers, the researches proposes that the soft-skills training programs based on the two major domains of human's professional excellence: Emotional Intelligence and Behavioural Intelligence.

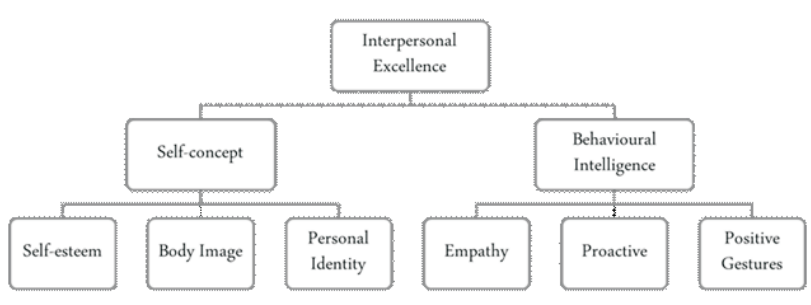

Fig 3 - Domains of interpersonal Excellence

The above figure reflects on the major intrapersonal and interpersonal skills required for nourishing effective interpersonal relationships at workplace. Moreover, it is also observed that most of the conflicts or any other distortions at workplace arise due to some petty annoyances. These petty annoyances are deep rooted in the emotional gamut of the individuals. Moreover, the emotions in an individual are the bi-products of one's selfconcept and it is this self-concept that influence the quality of his/her relationships with others.

In addition, the behavioural responses based on one's self concept have an immediate impact on the quality of human relations. This is very much evident during the day to day interactions of the employees at a workplace. Many researchers have proved that the quality of behavioural interactions or transactions that define the quality of human relations.

Considering the importance and interrelatedness of self-concept and behavioural intelligence, the researchers have identified a few tested pedagogical tools for training the students' interpersonal excellence. The 
following figure reflects on the proposed pedagogical tools:

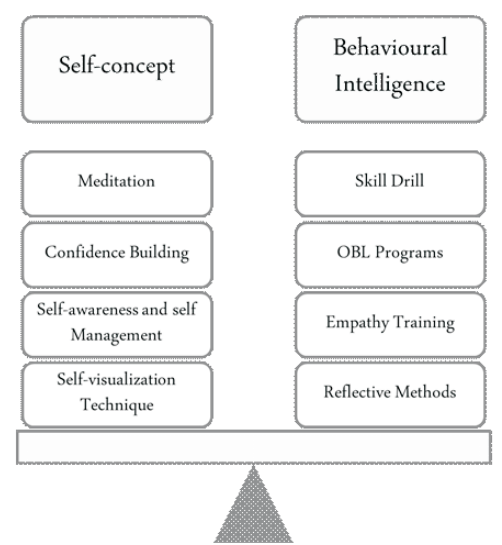

Fig 4 - Suggested pedagogical tools for enhancing interpersonal excellence

\section{Conclusion}

The study focused on developing interpersonal skills of the young professionals with reference to the interpersonal skills of the acumen professionals. Further, FIRO-B was adopted for instrumentation and it is also used as a touchstone for assessing and developing the interpersonal excellence. Further, the research also threw light on the required areas of interpersonal domain that have to be nourished. In this regard, the research discovered that the young professionals who are not yet exposed to the professional ambience have to be, predominantly, trained on the self-concept that would directly contribute to maintain healthy relationships at workplace.

Further, the researchers also contemplated on the productive pedagogical tools that canbe incorporatedduring the sessions of soft-skills training in an academic set-up.It is also presumed that training the students on interpersonal skills will enhance their work productivity, equip them with effective human dynamics and they will be enough wise in handling workplace conflicts.

\section{References}

1. A.K. Penthoi and S.Dash. (2005). Indian Higher Education in the Era of Globalization: Challenges \& Quality management strategies, University News.

2. Brian M. Alman, Peter T. Lambrou (1983), Self-Hypnosis: The Complete Guide to Better Health and Self-change, Philadelphia: Brunner/Mazel Pub.: 1992

3. Chakka, R., and Kulkarni, G.T. (2010). Total Quality Management in Pedagogy (TQM_P): An Update. Indian Pharm. Educ. Res. 44(4).

4. Datar, M. Srikant, Garvin, A. David \& Cullen, G. Patrick. (2010). Rethinking the MBA: Business Education a Crossroads. Boston: Harvard Business Press.

5. Schutz, W.C. (1958). FIRO: A Three Dimensional Theory of Interpersonal Behavior. New York, NY: Holt, Rinehart, \& Winston

6. Goleman, Daniel. (1996). Emotional Intelligence: Why it Can Matter More Than IQ. London: Bloomsbury Publishing. 